\title{
Distribution of Departures
}

\section{Nirmala Kasturi}

Abstract: Among all statistical empirical distributions, the distributionson departures most used one in practice. Several distributions have been developed by some transformations on the existing distributions.This paper proposes one truncated probability density function for selected random variable.

Key Words: Random variable, continuous probability distribution, departure rate, density function.

\section{INTRODUCTION}

The random variable of interest is instead of asking "In fixed time interval, how many departures take place?", "We ask in a particular interval how likely there are successive departures". We can say this random variableis continuous, if there exist truncated probability density $\mathrm{f}(\mathrm{x})$ which is continuous over the time axis with

$f(x)$ is greater than or equal to zero for all $x$

$$
\text { and also } \int_{-\infty}^{\infty} f(x) d x=1
$$

Here we restrict the number of arrivals (domain) to the queuing system. We allow $\mathrm{N}$ initially. Thus we consider truncated density function. The no. of persons remained later departing $\mathrm{N}-\mathrm{n}$ persons from the system after theservice. For $n=0$ means $N-N=0$ $n=1$ means $N-(N-1)=1\}$ Casesare absurd since we consider the two consecutive departures in the time interval.

Case a: When $\mathbf{n}$ is 1 : that isn $=\mathrm{N}-2$

We propose

$$
\begin{aligned}
& f(x)=\mu[2 P(N-(N-2), t)-P(N-(N-1), t)] \\
& f(x)=[\mu(2 P(2, t)-P(1, t))]
\end{aligned}
$$

Where $\mathrm{P}(1, \mathrm{t}), \mathrm{P}(2, \mathrm{t})$ are Truncated Poison probability distributions $P(1, t)=e^{-\mu t} \mu \mathrm{t}$

Revised Manuscript Received on December 15, 2019

Nirmala Kasturi, Assistant Professor, Sri Venkateshwara College of Pharmacy, Gachibowlli, Hyderabad, India.

E-mail: vaka.nirmalaprakash@gmail.com

$$
P(2, t)=\frac{e^{-\mu t}(\mu t)^{2}}{2 !}
$$

Since probability of departing 2 persons from a queuing system $\mathrm{P}(2, \mathrm{t})$ in time ' $\mathrm{t}$ ' is less than probability of departing 1 person $\mathrm{P}(1, \mathrm{t})$ from that system in same time ' $\mathrm{t}$ '.

Also twice the $P(2, t)$ is more than $P(1, t)$.

$\therefore(2 P(2, t)-(P(1, t))$ is a positive quantity.

$\mu$ is departing rate of the queuing system which is also

positive

$\therefore f(x)=\mu[2 P(2, t)-P(1, t)] \geq 0$

Now $\int_{-\infty}^{\infty} f(x) d x=\int_{0}^{\infty} f(x) d x=2 \int_{0}^{\infty} \mu P(2, t) d t-\int_{0}^{\infty} \mu P(1, t) d t$ $=2-1=1$

$\therefore f(x)$ is density function when $\mathrm{n}$ is 2 .

Case b: When $\mathbf{n}$ is 3: $\mathrm{n}$ is no. of customers remained in the system later departing $\mathrm{N}-3$ persons We propose

$f(x)=\mu[2 P(N-(N-3), t)-P(N-(N-2), t)]$

$f(x)=\mu[2 P(3, t)-P(2, t)]$

$P(3, t)=\frac{e^{-\mu t}(\mu t)^{3}}{3 !}$

$P(2, t)=\frac{e^{-\mu t}(\mu t)^{2}}{2 !}$

$\mu$ is departing rate of the queuing system which is also positive.

Since the probability of departing 3 persons from a queuing system $\mathrm{P}(3, \mathrm{t})$ in time ' $\mathrm{t}$ ' is less than probability of departing 2persons $\mathrm{P}(2, \mathrm{t})$ from that system in same time ' $\mathrm{t}$ ' .

Also twice the $\mathrm{P}(3, \mathrm{t})$ is more than $\mathrm{P}(2, \mathrm{t})$ 


\section{Distribution of Departures}

$\therefore(2 P(3, t)-(P(2, t))$ is a positive quantity.

II. EMPIRICAL STUDY

$\therefore f(x)=\mu[2 P(3, t)-P(2, t)] \geq 0$

Now $\int_{-\infty}^{\infty} f(x) d x=\int_{0}^{\infty} f(x) d x=2 \int_{0}^{\infty} \mu P(3, t) d t-\int_{0}^{\infty} \mu P(2$,

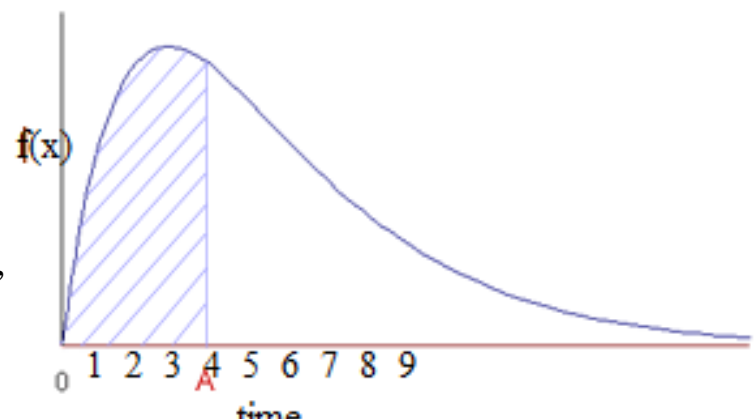

$=2-1=1$

$\therefore f(x)$ is density function when $\mathrm{n}$ is 3 .

\section{Case $c$ : When $n$ is 4}

$\mathrm{n}$ is the no. of customers left in the system later departing $\mathrm{N}$ -4 persons. We propose

$$
\begin{aligned}
& f(x)=\mu[2 P(N-(N-4), t)-P(N-(N-3), t)] \\
& f(x)=\mu[2 P(4, t)-P(3, t)]
\end{aligned}
$$

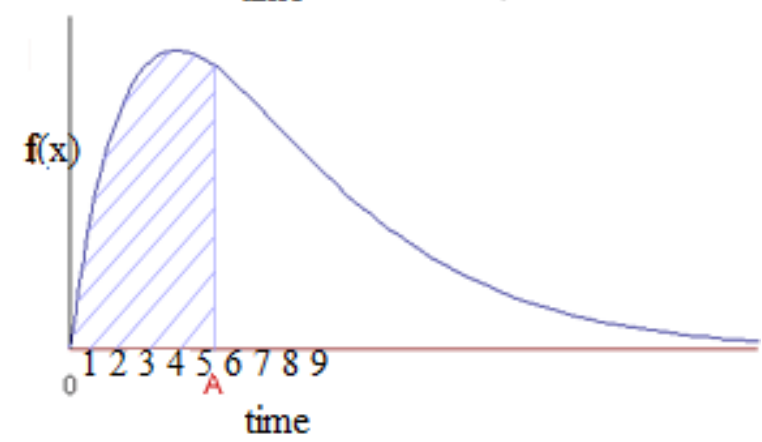

FIGURE - A

FIGURE - B

The truncated Poisson probability distributions

$$
\begin{aligned}
& P(4, t)=\frac{e^{-\mu t}(\mu t)^{4}}{4 !} \\
& P(3, t)=\frac{e^{-\mu t}(\mu t)^{3}}{3 !}
\end{aligned}
$$

$\mu$ is departure rate of the queuing system which is positive.

Since the probability of de0parting 4persons from a queuing system $\mathrm{P}(4, \mathrm{t})$ in time ' $\mathrm{t}$ ' is less than probability of departing 3persons $\mathrm{P}(3, \mathrm{t})$ from that system in same time ' $\mathrm{t}$ ' .

Also twice $\mathrm{P}(4, \mathrm{t})$ is more than $\mathrm{P}(3, \mathrm{t})$

$\therefore(2 P(4, t)-(P(3, t))$ is a positive quantity.

$\therefore f(x)=\mu[2 P(4, t)-P(3, t)] \geq 0$

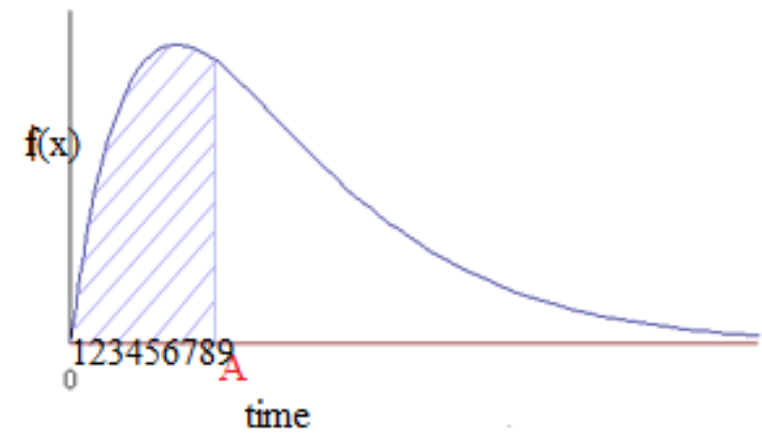

\section{FIGURE - C}

$\mathrm{X}$ axis -time and $\mathrm{Y}$ axis - $\mathrm{f}(\mathrm{x})$.

Shaded region is probability of arriving consecutive arrivals in the interval $[0, \mathrm{~A}]$.

The probability density curve is not symmetric. When it comes to generalization, we need to normalize to keep the area under the curve equals to one.In general we consider for the random variable of the successive departures we specify thep.d.f. below.

$$
f(x)=\left\{\begin{array}{l}
\left.2 \mathfrak{I}^{\prime} P(n, x)-P(n-1, x)\right) \quad \text { when } t \geq 0 \\
0 \text { otherwise }
\end{array}\right.
$$

where $\mathfrak{J}^{\prime}$ is the normalizing constant.

Now $\int_{-\infty}^{\infty} f(x) d x=\int_{0}^{\infty} f(x) d x=2 \int_{0}^{\infty} \mu P(4, t) d t-\int_{0}^{\infty} \mu P(3$ The probability of consecutive departures increases when $=2-1=1$ 


\section{CONCLUSION}

In this paper we presentedfor the random variable of the successive departures, theprobability density function,

$f(x)=\left\{\begin{array}{l}\left.2 \mathfrak{J}^{\prime} P(n, x)-P(n-1, x)\right) \quad \text { when } t \geq 0 \\ 0 \text { otherwise }\end{array}\right.$

\section{FUTURE WORK}

We can find CDF, standard deviation, mean and variance of the above distribution.

\section{REFERENCES}

1] Daisuke Nakezato, Demitriics Bertsimas The distributional Little's law and its applications, (with D.Nakazato), Operations Research, 43, 2 , 298-310, MIT, 1995 .

[2] DemitriicsBertsimas An analytic approach to a general class of G/G/s queuing systems, Operations Research, 38, 1, 139-155, MIT, 1990.

[3]Hamdy Taha: Operations research An Introduction, seventh edition, pearson education.

[4] James M Thomson and Donald Gross; Fundamentals of Queueing theory, Third addition, 2002: Wiley series.

[5] Janus Sztrik, Queueing theory and its applications; A personal view by Proceedings of the 8th International conference on Applied Informatics, Eger, Hungary, Jan 27-30, 2010, Vol.1, PP.9-30.

[6] Jeffrey Herrman: A survey of Queueing theory Applications in Healthcare, SamueFomundam ISR Technical Report 2007-24.

[7] J-P Cletch, D.M.Noctor, J.C.Manock, G.W.Lynott and F.E.Bader; Surface Mount Assembly failure statistics and failure free items AT\&T Bell laboratories, $44^{\text {th }}$ ECTC, Washington, D.C, May 1-4, 1994, PP.293-297.

[8] Michael D. Peterson, Dimitris J. Bertsimas, Amedeo R. Odoni; MIT, Models and algorithms for Transient Queueing Congestion a Airports, Management science, volume 41, 1279-1295, 1995.

[9] NolnPlumchitchom and Nick T. Thomopoulos; The Queueing theory of the Erlang Distributed Inter arrival and Service Time, Journal of Research in Engineering and Technology, Vol.3, No.4, OctoberDecember 2006.

[10] S.D. Sharma; Operations research, Fourteenth addition, 2003, Kedarnadh and Ramnadh and co. publishers.

[11] W. Weibull "A statistical distribution function of wide applicability" Journal of applied Mechanics, September 1951, pp 293-297.

[12] R.Luus and Jammer; Estimation of parameters in 3 parameter Weibull probability distribution functions, $10^{\text {th }}$ international workshop on Chemical Engineering Mathematics, Budapet, Hungary, August 18-20 (2005).

[13] Patric O'Conner, Reliability Engineering, $5^{\text {th }}$ Edition, 2012, Wiley Series.

[14] William W. Hines, Douglas C. Montgomerry, David M.Goldsman, Connie M. Borrer, probability and Statistics in Engineering, Fourth Edition, Wiley Series.

[15] Vijay K. Rohatgi, A.K.Md. Ehsanes Saleh, An Introduction to Probability And Statistics, Second Edition, Wiley Series.

[16] Kishore S. Trivedi, Probability \& Statistics with Reliability, Queueing And Computer Science Applications, Second Edition, Wiley Series.

[17] Ravindran, Phillips, Solberg, Operations Research principles and practice, Second Edition, Wiley series.

[18] R.Sreeparimala, S.PalaniammalBulk Service Queueing Model With Services Single and Delayed Vacation, International Journal of Advances in Science and Technology(IJAST), Vol 2, Issue 2, June 2014.

[19] J. D. C. Little, "A Proof for the Queuing Formula: Operations Research, vol. 9(3), 1961, pp. 383-387, doi: 10.2307/167570.

[20] M. Laguna and J. Marklund, Business Process Modeling, Simulation and Dsign, Pearson Prentice Hall, 2005.

[21] Gamarnik, On the Undecidability of Computing Stationary Distributions and Large Deviation Rates for Constrained Random Walks, Mathematics of Operations Research, 2007, Vol. 32, 257-265.
[22] Gamarnik, Katz, On Deciding Stability of Multiclass Queueing Networks under Buffer Priority Scheduling Policies, Mathematics of Operations Research, 2009, Vol. 19, 2008-2037.

[23] Ajeet Kumar Pandey, Srinivas Panchangam, Jessy George Smith, Safety analysis of Automatic Door operation for Metro Train : A case study. $9^{\text {th }}$ International conference on Heterogeneous Networking for quality, reliability Robustness, January 11-12-2013, Greater Noida, India.

[24] Wallace Agiel, Christian Asave, Modeling and Analysis of Queueing Systems in Banks, International Journal of Scientific Technology, Volume 4, Issue 7, July 2015.

[25] T.L. Pap and L. Leiszner, The use of Queueing Theory for planning automated analytical systems, Journal of Automated Chemistry, volume 9, No. 2 (April- June 1987), p.p 87-91.

[26] X. Papaconstantinou, On the exact steady state solution of the Ek/C2/s queue, European Journal of Operations Research, 37(2), 272-287, 1988.

[27] J Keilson, D, Nakazato, H, Transient and busy period analysis of the GI/G/1 queue as a Hilbert factorization problem, Journal of Applied Probability, 28, 873-885, 1991 